\title{
MALDI-TOF Mass Spectrometry in Microbiology
}

Edited by: Markus Kostrzewa and Sören Schubert

Bruker Daltonik GmbH, Bremen, Germany and Max von Pettenkofer-Institut, Munich, Germany; respectively

Published: June 2016. Pages: $x+170$

ISBN: Book: 978-1-910190-41-8. Ebook: 978-1-910190-42-5£159, \$319

Published by: Caister Academic Press www.caister.com

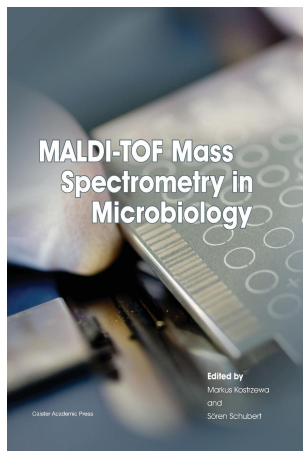

Recent years have seen a phenomenal increase in the use of MALDI-TOF mass spectrometry (MALDI-TOF MS) in microbiology laboratories. The introduction of this technology to microbiology has been a major success and MALDI-TOF MS is now used for routine diagnostic or diagnostic-like purposes in clinic, veterinary, pharma and food microbiology laboratories. It has also evolved into a powerful tool for the analysis of organisms in the environment and for research into microbial communities. The throughput capabilities, accuracy and low running costs of a MALDI-TOF MS system enable analyses at a scale which was not possible until recently.

In this timely and up-to-date book, experts in the field provide an overview of the application of MALDI-TOF MS in key areas of microbiology and discuss the impact this modern technology is having on laboratory practice and patient outcome. Several chapters cover applications in clinical and veterinary diagnostic laboratories, food microbiology, environmental microbiology and strain collections. Further chapters discuss the utilization of MALDI-TOF MS for the analysis of challenging microbial groups such as yeast and anaerobic bacteria. In addition, new applications such as microbial typing, DNA analysis and the detection of antibiotic resistance are also covered. The final chapter provides a valuable overview of potential future trends and developments in MALDI-TOF MS and assesses the impact of the technology in microbiology.

This authoritative volume will be indispensable for all microbiology laboratories.

Introduction. A Personal Vision of the MALDI-TOF-MS Journey from Obscurity to Frontline Diagnostics (Haroun N. Shah) Chapter 1. Matrix Assisted Laser Desorption Ionization Time-of-Flight Mass Spectrometry for the Clinical Laboratory (Chris D. Doern, Robert C. Jerris and Mark D. Gonzalez)

Chapter 2. Analysis of Anaerobes and Some Other Fastidious Bacteria (Elisabeth Nagy)

Chapter 3. Identification, Typing and Susceptibility Testing of Fungi (incl. Yeasts) by MALDI-TOF MS (Anna Kolecka, Maurizio Sanguinetti, Teun Boekhout and Brunella Posteraro)

Chapter 4. Molecular Typing of Bacteria/Fungi Using MALDI-TOF MS (Silpak Biswas, Frédérique Gouriet and Jean-Marc Rolain)

Chapter 5. Matrix-assisted Laser Desorption/lonization Time-of-flight Mass Spectrometry for Determination of Resistance to Antibiotics (Jaroslav Hrabák, Monika Dolejská and Costas C. Papagiannitsis)

Chapter 6. Application of MALDI-TOF MS in Veterinary and Food Microbiology (Claudia Hess, Merima Alispahic and Michael Hess)

Chapter 7. MALDI-TOF MS for Environmental Analysis, Microbiome Research and as a Tool for Biological Resource Centres (Markus Kostrzewa, Chantal Bizet and Dominique Clermont)

Chapter 8. The World of Nucleic Acid Based Mass Spectrometry for Microbial and Viral Detection (Christiane Honisch)

Chapter 9. Future Trends and Perspectives of MALDI-TOF Mass Spectrometry in the Microbiology Laboratory (Sören

Schubert and Markus Kostrzewa)

Order from:

Caister Academic Press https://www.caister.com/order 


\section{CURRENT BOOKS OF INTEREST}

Porcine Viruses: From Pathogenesis to Strategies for Control

Edited by: Hovakim Zakaryan (Published: 2019)

Lactobacillus Genomics and Metabolic Engineering

Edited by: Sandra M. Ruzal (Published: 2019)

Cyanobacteria: Signaling and Regulation Systems

Author: Dmitry A. Los (Published: 2018)

Viruses of Microorganisms

Edited by: Paul Hyman and Stephen T. Abedon (Published: 2018)

Protozoan Parasitism: From Omics to Prevention and Control

Edited by: Luis Miguel de Pablos Torró and Jacob-Lorenzo Morales (Published: 2018)

Genes, Genetics and Transgenics for Virus Resistance in Plants

Edited by: Basavaprabhu L. Patil (Published: 2018)

DNA Tumour Viruses: Virology, Pathogenesis and Vaccines

Edited by: Sally Roberts (Published: 2018)

Pathogenic Escherichia coli: Evolution, Omics, Detection and Control

Edited by: Pina M. Fratamico, Yanhong Liu and Christopher H. Sommers (Published: 2018)

Postgraduate Handbook: A Comprehensive Guide for PhD and Master's Students and their Supervisors

Author: Aceme Nyika (Published: 2018)

Enteroviruses: Omics, Molecular Biology, and Control

Edited by: William T. Jackson and Carolyn B. Coyne (Published: 2018)

"frontiers in the study of the 12 species of the genus" (ProtoView); "the current most important enterovirus research"

(Biotechnol. Agron. Soc. Environ.)

Molecular Biology of Kinetoplastid Parasites

Edited by: Hemanta K. Majumder (Published: 2018)

Bacterial Evasion of the Host Immune System

Edited by: Pedro Escoll (Published: 2017)

"The figures are expertly drawn" (SIMB News)

Illustrated Dictionary of Parasitology in the Post-Genomic Era

Author: Hany M. Elsheikha and Edward L. Jarroll (Published: 2017)

"a guide for students, academic staff, medical and veterinarian professionals" (ProtoView); "an extensive and comprehensive glossary of contemporary concepts, terminologies, and vocabulary in modern parasitology" (Doodys); "a pure pleasure to explore and discover" (Epidemiol. Infect.); "highly recommended" (Biotechnol. Agron. Soc. Environ.)

Next-generation Sequencing and Bioinformatics for Plant Science

Edited by: Vijai Bhadauria (Published: 2017)

The CRISPR/Cas System: Emerging Technology and Application

Edited by: Muhammad Jamal (Published: 2017)

"reviews recent advances" (ProtoView)

Brewing Microbiology: Current Research, Omics and Microbial Ecology

Edited by: Nicholas A. Bokulich and Charles W. Bamforth (Published: 2017)

"a valuable information source ... an authoritative overview" (IMA Fungus); "a must read book" (SIMB News)

Metagenomics: Current Advances and Emerging Concepts

Edited by: Diana Marco (Published: 2017)

"presents those new to the field with important aspects of metagenomics" (Eur. J. Soil Sci.)

Bacillus: Cellular and Molecular Biology (Third edition)

Edited by: Peter L. Graumann (Published: 2017)

"a one-stop shop for a huge range of Bacillus-focused molecular biology" (Microbiology Today) 